\title{
Comportamento ingestivo de novilhas leiteiras alimentadas com polpa cítrica em substituição ao feno de capim-tifton $85^{1}$
}

\section{Josué Mendes Neto ${ }^{2}$, José Maurício de Souza Campos ${ }^{3}$, Sebastião de Campos Valadares Filho $^{3}$, Rogério de Paula Lana ${ }^{3}$, Augusto César de Queiroz ${ }^{3}$, Ricardo Frederico Euclydes ${ }^{3}$}

\footnotetext{
1 Parte da tese do primeiro autor apresentada à Universidade Federal de Viçosa para obtenção do título de Magister Scientiae em Zootecnia. 2 Doutorando, DZO-UFV, Viçosa-MG, CEP: 36571-000.

${ }^{3}$ Departamento de Zootecnia, Universidade Federal de Viçosa, Viçosa-MG, CEP: 36571-000.
}

RESUMO - Objetivou-se avaliar o comportamento ingestivo de novilhas leiteiras em confinamento alimentadas com polpa cítrica em substituição ao feno de capim-tifton 85 (Cynodon cactylon (L.) Pear). Utilizaram-se 28 novilhas holandesas com 12 meses de idade e peso inicial de $184 \mathrm{~kg}$. Os animais foram distribuídos em delineamento em blocos casualizados com quatro tratamentos e sete blocos, sendo os animais agrupados conforme o peso médio inicial. As dietas experimentais consistiam de quatro níveis de substituição $(0,16,6,33,3$ e 50\%) do feno de capim-tifton 85 por polpa cítrica. Foram preparadas quatro misturas concentradas, objetivando que as dietas tivessem o mesmo teor de PB e nitrogênio não-protéico (NNP). A substituição do feno pela polpa cítrica provocou redução no tempo despendido em alimentação, ruminação e mastigação total (min/dia), mas não afetou o número de mastigações merícicas. A eficiência de alimentação e ruminação em g MS/h aumentou à medida que o feno foi substituído pela polpa cítrica. A eficiência de alimentação e ruminação em g FDN/h, no entanto, não foi influenciada pelos níveis de substituição do feno pela polpa cítrica. A polpa cítrica, quando utilizada em substituição ao feno de tifton, diminui os tempos de alimentação, ruminação e mastigação e modifica o comportamento ingestivo dos animais.

Palavras-chave: mastigação, taxa de alimentação, tempo de alimentação, tempo de ruminação

\section{Chewing activity of dairy heifers fed diets with partial replacement of Tifton 85 hay with citrus pulp}

\begin{abstract}
The objective of this trial was to evaluate the chewing activity of dairy heifers fed diets in which Tifton 85 hay (Cynodon dactylon (L.) Pear) was partially replaced by citrus pulp. Twenty-eight Holstein dairy heifers averaging 12 months of age and $184 \mathrm{~kg}$ of BW at the beginning of the trial were blocked by initial BW and, within each block (7 blocks), randomly assigned to one of the following four treatments: $0,16.6,33.3$, or $50 \%$ of a concentrate based on citrus pulp that partially replaced Tifton 85 hay in the diet. Diets were formulated to be isonitrogenous. It was observed linear reductions at the time spent eating, ruminating, and total chewing time (min/day) when citrus pulp was increased in the diet. However, the number of chews during ruminating was not affected by partially replacing Tifton 85 hay with citrus pulp. Although eating and ruminating efficiencies increased linearly when expressed in $\mathrm{g}$ of $\mathrm{DM} / \mathrm{h}$, both variables did not differ when expressed in $\mathrm{g} N \mathrm{ND} / \mathrm{h}$ across treatments. Replacing Tifton 85 hay with citrus pulp decreased eating, ruminating, and total chewing times leading to significant changes in the overall chewing activity of dairy heifers.
\end{abstract}

Key Words: chewing, feeding rate, feeding time, rumination time

\section{Introdução}

O estudo do comportamento ingestivo de animais ruminantes é fundamental para o entendimento dos processos de digestão dos alimentos, sua eficiência de utilização e absorção e da manutenção das condições ruminais. O consumo diário de alimentos pode ser descrito pelo número de refeições consumidas por dia, pela duração das refeições e pela taxa de alimentação, ou seja, a velocidade em que cada refeição é feita. Cada um desses processos é resultado de uma complexa interação metabolismo do animal $\times$ propriedades físicas e químicas da dieta (Thiago et al., 1992), sendo determinantes do consumo de alimento e da eficiência de utilização do alimento pelo animal. A atividade de mastigação está associada à taxa de secreção salivar, à solubilização de componentes do alimento e à quebra de partículas, facilitando os processos de colonização dessas partículas pelos microrganismos ruminais e de digestão, o que influencia a taxa de passagem, o tempo de retenção e, conseqüentemente, a digestibilidade dos alimentos. Segundo 
Dado \& Allen (1995), o completo entendimento da atividade de consumo diário pode ser alcançado apenas se seus componentes individuais forem estudados.

As propriedades físicas e químicas da dieta influenciam o tempo gasto pelo animal na atividade de ruminação, sendo proporcional ao teor de parede celular dos volumosos (Van Soest, 1994). O tempo de ruminação difere entre alimentos concentrados e volumosos, sendo menor para concentrados e alimentos finamente triturados ou peletizados quando comparado ao mesmo alimento in natura. Segundo Poppi et al. (1987), muitos fatores influenciam o consumo de forragem em animais em pastejo e estes fatores podem ser grosseiramente classificados como nutricionais e não nutricionais. Fatores nutricionais como digestibilidade, tempo de retenção do alimento no rúmen e concentração de produtos metabólicos parecem ser importantes no controle da ingestão de alimento somente se o acesso e a disponibilidade de forragem não forem limitados, ou seja, se a capacidade de colheita do animal não for limitada pela quantidade de forragem disponível, pela altura da pastagem e pela massa e densidade de forragem. Em situações em que as características da pastagem limitam a apreensão do alimento pelo animal, os fatores não-nutricionais, como disponibilidade de forragem, passam a ser mais importante que os nutricionais em determinar o consumo.

Em condições de alimentação não competitiva de animais em confinamento, onde não há restrição à quantidade de alimento fornecido, o tempo de alimentação e ruminação é influenciado pelas características do alimento, principalmente seu teor de parede celular. Segundo Welch (1982), o comportamento ingestivo do animal varia de acordo com as características do alimento, como recurso para manter o consumo de nutrientes e seu potencial produtivo. Esses autores observaram, no entanto, que esta capacidade adaptativa é limitada e que o aumento do fornecimento de fibra indigestível não incrementa o tempo de ruminação em mais de 8 ou 9 horas por dia. Dado \& Allen (1995), em estudo com vacas leiteiras alimentadas com dietas formuladas com diferentes teores de FDN, com ou sem adição de material inerte, verificaram que os tempos gastos com alimentação, ruminação e mastigação aumentam com o incremento do teor de FDN da dieta e a com adição de material inerte, como consequiência do maior número de mastigação total, de alimentação e ruminação por dia.

Deswysen et al. (1987), em estudo com animais alimentados ad libitum com silagem de milho, com ou sem a adição de monensina, observaram que o tempo unitário de ruminação, expresso em minuto/kg de MS, foi positivamente correlacionadoà duração do período de ruminação, ao número de períodos de ruminação, ao número de movimentos ruminativos por bolo e ao número de contrações retículoruminais, sendo, contudo, negativamente correlacionado ao nível de consumo voluntário de MS e ao tempo de alimentação.

A mastigação reduz o tamanho das partículas e hidrata o alimento durante a insalivação, liberando nutrientes solúveis para fermentação, o que influencia o crescimento microbiano, além de expor a fração fibrosa do alimento à colonização microbiana (Beauchemin et al., 1994). Segundo Ulyatt et al. (1986), as funções principais das mastigações ingestivas, em concomitância à insalivação, são formação do bolo alimentar, liberação dos componentes solúveis e degradação dos tecidos vegetais facilitando a colonização pelos microrganismos. As mastigações merícicas, no entanto, estão relacionadas à redução do tamanho das partículas e ao aumento da probabilidade de escape pelo orifício retículo-omasal e de sua passagem ao trato digestivo posterior.

Dietas com alta relação concentrado:volumoso são comumente associadas a distúrbios ruminais como acidose, paraqueratose do epitélio ruminal, timpanismo, laminite, displasia do abomaso, entre outros. Ressalta-se também a necessidade de animais ruminantes serem alimentados com dietas que atendam não só às exigências em nutrientes como também ao mínimo de fibra para manutenção do ambiente ruminal estável. Assim, para vacas em balanço energético negativo e animais de alto potencial produtivo alimentados com dietas com alta proporção de concentrado, tem-se dado preferência à utilização de subprodutos como polpa cítrica e de beterraba (Welch \& Smith, 1971), por sua composição intermediária entre a maioria dos alimentos concentrados, e forragens, por seu teor e padrão de fermentação da fibra.

Objetivou-se nesta pesquisa avaliar a substituição do feno de capim-tifton 85 pela polpa cítrica e seus efeitos sobre o comportamento ingestivo de novilhas leiteiras (freqüência diária de consumo e ruminação, tempos de alimentação, ruminação e mastigação, número e duração das refeições, períodos de ruminação, características de mastigação) e a eficiência de alimentação e ruminação da MS e FDN.

\section{Material e Métodos}

O experimento foi conduzido no período de 16 de junho a 22 de setembro de 2000 na Unidade de Pesquisa, Ensino e Extensão em Gado de Leite (UEPE-GL) do Departamento de Zootecnia da Universidade Federal de Viçosa (Viçosa MG). As características climáticas de temperatura, umidade relativa do ar e precipitação durante o período experimental, coletadas na Estação Meteorológica do Departamento de Engenharia Agrícola da UFV, são descritas na Tabela 1. 
Vinte e oito novilhas holandesas malhadas de preto, puras e mestiças, com grau de sangue variando de $7 / 8$ Holandês-Zebu a puro por cruza (PC), com 12 meses de idade e peso inicial de $184 \mathrm{~kg}$ foram alojadas em baias individuais cobertas e separadas por cordoalha. As baias totalizavam $8 \mathrm{~m}^{2}$ de área $\left(5,6 \mathrm{~m}^{2}\right.$ de piso cimentado e $2,4 \mathrm{~m}^{2}$ de cama) e eram equipadas com comedouros individuais de concreto e bebedouros automáticos. Como cama, utilizou-se casca de café (material absorvente) previamente misturada a esterco bovino para evitar consumo pelos animais.

O experimento constou de 15 dias de adaptação às dietas, ao manejo e às instalações e três períodos experimentais de
28 dias, perfazendo 84 dias de coleta de dados. Os tratamentos consistiram de quatro níveis de substituição $(0 ; 16,6 ; 33,3$ e $50 \%$ ) do feno de tifton 85 (Cynodon dactylon (L.) Pear) por polpa cítrica. As dietas foram formuladas segundo as exigências nutricionais descritas pelo NRC (1989) para ganhos de peso médios diários de $700 \mathrm{~g}$. Foram preparadas quatro misturas concentradas para que as dietas fossem isoprotéicas e contivessem o mesmo teor de nitrogênio não-protéico (NNP). A composição percentual do concentrado e das dietas experimentais é apresentada na Tabela 2.

A dieta foi fornecida duas vezes ao dia, às $7 \mathrm{e} 17 \mathrm{~h}$, sendo o concentrado e o feno misturados e a quantidade fornecida

Tabela 1 - Temperatura média, média das temperaturas máximas e mínimas, umidade relativa do ar média e precipitação no período de junho a setembro de 2000

Table 1 - Weather conditions during the period of June to September of 2000

\begin{tabular}{|c|c|c|c|c|c|}
\hline \multirow[t]{2}{*}{$\begin{array}{l}\text { Mês } \\
\text { Month }\end{array}$} & \multicolumn{3}{|c|}{$\begin{array}{c}\text { Temperatura }\left({ }^{\circ} \mathrm{C}\right) \\
\text { Temperature }\left({ }^{\circ} \mathrm{C}\right) \\
\end{array}$} & \multirow[t]{2}{*}{$\begin{array}{l}\text { Umidade relativa do ar média (\%) } \\
\text { Relative humidity of the air }(\%)\end{array}$} & \multirow[t]{2}{*}{$\begin{array}{c}\text { Precipitação }(\mathrm{mm}) \\
\text { Precipitation }(\mathrm{mm})\end{array}$} \\
\hline & $\begin{array}{l}\text { Mínima } \\
\text { Minimum }\end{array}$ & $\begin{array}{l}\text { Máxima } \\
\text { Maximum }\end{array}$ & $\begin{array}{l}\text { Média } \\
\text { Average }\end{array}$ & & \\
\hline $\begin{array}{l}\text { Junho } \\
\text { June }\end{array}$ & 10,62 & 24,79 & 16,18 & 85,05 & 14,4 \\
\hline $\begin{array}{l}\text { Julho } \\
\text { July }\end{array}$ & 11,38 & 22,76 & 15,71 & 85,65 & 13,6 \\
\hline $\begin{array}{l}\text { Agosto } \\
\text { August }\end{array}$ & 11,68 & 25,67 & 17,56 & 82,72 & 19,1 \\
\hline $\begin{array}{l}\text { Setembro } \\
\text { September }\end{array}$ & 15,50 & 24,39 & 18,94 & 86,42 & 82,9 \\
\hline
\end{tabular}

Tabela 2 - Composição percentual dos concentrados e das dietas experimentais, com base na MS

Table 2 - Ingredient composition of diets and concentrates (\% of DM)

\begin{tabular}{|c|c|c|c|c|}
\hline \multirow[t]{2}{*}{$\begin{array}{l}\text { Ingrediente } \\
\text { Ingredient }\end{array}$} & \multicolumn{4}{|c|}{$\begin{array}{c}\text { Nível de substituição (\%) } \\
\text { Replacement level (\%) }\end{array}$} \\
\hline & 0 & 16,6 & 33,3 & 50 \\
\hline & \multicolumn{4}{|c|}{ Composição do concentrado (Concentrate composition) } \\
\hline Polpa cítrica (\%) (Citrus pulp) & 0,00 & 27,95 & 43,73 & 53,82 \\
\hline Milho (\%) (Ground corn) & 85,49 & 53,52 & 34,67 & 22,62 \\
\hline Farelo de soja (\%) (Soybean meal) & 6,67 & 4,80 & 3,75 & 3,08 \\
\hline Farelo de algodão (\%) (Cottonseed meal) & 0,00 & 9,39 & 14,93 & 18,49 \\
\hline Uréia $(\%)$ (Urea) & 1,00 & 0,72 & 0,56 & 0,46 \\
\hline Fosfato bicálcico (\%) (Dicalcium phosphate) & 4,42 & 2,63 & 1,59 & 0,90 \\
\hline Calcário calcítico (\%) (Limestone) & 1,06 & 0,00 & 0,00 & 0,00 \\
\hline Sal mineral (\%) (Mineral salt) & 1,36 & 0,98 & 0,76 & 0,63 \\
\hline \multirow[t]{2}{*}{ BHT g/100kg } & 3,00 & 3,00 & 3,00 & 3,00 \\
\hline & \multicolumn{4}{|c|}{ Composição da dieta (Diet composition) } \\
\hline Feno de tifton 85 (\%) (Tifton 85 hay) & 70,00 & 58,34 & 46,66 & 35,00 \\
\hline Polpa cítrica (\%) (Citrus pulp) & 0 & 11,65 & 23,33 & 35,00 \\
\hline Milho (\%) (Ground corn) & 25,65 & 22,30 & 18,49 & 14,71 \\
\hline Farelo de soja $(\%)$ (Soybean meal) & 2,00 & 2,00 & 2,00 & 2,00 \\
\hline Farelo de algodão (\%) (Cottonseed meal) & 0 & 3,91 & 7,95 & 12,02 \\
\hline Uréia $(\%)$ (Urea) & 0,30 & 0,30 & 0,30 & 0,30 \\
\hline Fosfato bicálcico (\%) (Dicalcium phosphate) & 1,33 & 1,10 & 0,85 & 0,58 \\
\hline Calcário calcítico (\%) (Limestone) & 0,32 & 0 & 0 & 0 \\
\hline Sal mineralizado $(\%)$ (Mineral salt) & 0,41 & 0,41 & 0,41 & 0,41 \\
\hline Butil-hidroxi-tolueno (BHT) g/100 kg & 0,9 & 1,25 & 1,60 & 1,95 \\
\hline
\end{tabular}


Tabela 3 - Composição química do feno de tifton 85, dos concentrados e das dietas Table 3 - Chemical composition of Tifton 85 hay, concentrates and diets

\begin{tabular}{|c|c|c|c|c|c|c|c|c|c|c|}
\hline \multirow[t]{3}{*}{$\begin{array}{l}\text { Item }(\%) \\
\text { Item }(\%)\end{array}$} & \multirow[t]{3}{*}{$\begin{array}{l}\text { Polpa cítrica } \\
\text { Citrus pulp }\end{array}$} & \multirow[t]{3}{*}{$\begin{array}{l}\text { Feno } \\
\text { Hay }\end{array}$} & \multicolumn{8}{|c|}{$\begin{array}{c}\text { Nível de substituição (\%) } \\
\text { Replacement level (\%) }\end{array}$} \\
\hline & & & \multicolumn{4}{|c|}{$\begin{array}{l}\text { Concentrado } \\
\text { Concentrate }\end{array}$} & \multicolumn{4}{|c|}{$\begin{array}{l}\text { Dieta } \\
\text { Diet }\end{array}$} \\
\hline & & & 0 & 16,6 & 33,3 & 50 & 0 & 16,6 & 33,3 & 50 \\
\hline $\operatorname{MS}(D M)$ & 88,7 & 90,72 & 87,59 & 87,66 & 87,50 & 87,59 & 89,78 & 89,43 & 89,01 & 88,69 \\
\hline MO (OM) & 93,15 & 93,08 & 91,44 & 92,01 & 92,88 & 92,89 & 92,59 & 92,63 & 92,97 & 92,96 \\
\hline $\mathrm{PB}(C P)$ & 7,50 & 14,41 & 13,48 & 13,74 & 13,89 & 13,99 & 14,13 & 14,13 & 14,13 & 14,13 \\
\hline $\mathrm{NNP}(N P N)^{1}$ & 21,31 & 21,15 & 22,78 & 22,59 & 22,20 & 21,94 & 21,62 & 21,74 & 21,70 & 21,66 \\
\hline NIDA $(A D I N)^{1}$ & 38,96 & 29,35 & - & - & - & - & - & - & - & - \\
\hline $\mathrm{EE}(E E)$ & 3,10 & 2,00 & 4,72 & 3,72 & 3,60 & 3,57 & 2,82 & 2,72 & 2,85 & 3,02 \\
\hline $\mathrm{CT}(T C)$ & 77,01 & 76,68 & 73,24 & 74,56 & 75,39 & 75,33 & 75,64 & 75,79 & 75,99 & 75,80 \\
\hline FDN (NDF) & 25,15 & 71,70 & 9,72 & 13,80 & 16,23 & 18,07 & 53,01 & 47,38 & 42,30 & 36,84 \\
\hline $\mathrm{CNF}(N F C)$ & 53,0 & 4,98 & 63,52 & 60,75 & 59,16 & 57,26 & 22,54 & 28,40 & 33,69 & 38,96 \\
\hline FDA $(A D F)$ & 22,7 & 31,56 & 1,69 & 5,55 & 6,45 & 9,50 & 22,60 & 20,64 & 18,25 & 17,22 \\
\hline HEM & 9,60 & 33,48 & 6,77 & 6,86 & 6,47 & 6,88 & 25,47 & 22,30 & 19,17 & 16,19 \\
\hline CEL & 16,81 & 27,21 & 2,12 & 5,05 & 6,76 & 8,73 & 19,68 & 17,90 & 16,37 & 15,20 \\
\hline LIG & 2,6 & 4,38 & 0,61 & 1,37 & 1,62 & 2,18 & 3,22 & 3,11 & 2,91 & 2,95 \\
\hline $\mathrm{NDT}(T D N)$ & - & - & - & - & - & - & 73,85 & 72,96 & 72,68 & 71,16 \\
\hline Cinzas (Ash) & 11,02 & 6,92 & 8,56 & 7,99 & 7,12 & 7,11 & 7,41 & 7,37 & 7,03 & 7,04 \\
\hline $\mathrm{Ca}$ & 1,80 & 0,54 & 1,91 & 1,74 & 1,31 & 1,43 & 0,95 & 1,04 & 0,95 & 1,12 \\
\hline $\mathrm{P}$ & 0,09 & 0,24 & 1,39 & 1,20 & 0,80 & 0,83 & 0,58 & 0,64 & 0,56 & 0,63 \\
\hline
\end{tabular}

$1 \%$ do $\mathrm{N}$ total (\% of total $\mathrm{N}$ ).

calculada para permitir aproximadamente $10 \%$ de sobras, para garantia de ingestão voluntária e seleção uniforme pelos animais. As sobras eram retiradas semanalmente, quando era feita a amostragem. As amostras foram devidamente identificadas e armazenadas a $-5^{\circ} \mathrm{C}$. O feno e o concentrado fornecido aos animais foram amostrados diariamente para a formação, ao final do experimento, de uma amostra composta de feno, concentrado e sobras, por animal, em cada período experimental.

As amostras do alimento fornecido e das sobras foram secas em estufa de ventilação forçada a $65^{\circ} \mathrm{C}$ e processadas em moinho tipo Willey equipado com peneira de $1 \mathrm{~mm}$. Os teores de MS, MO, NT, EE, fósforo inorgânico total e cálcio foram determinados conforme técnica descrita por Silva (1990) e os de FDN e FDA, segundo procedimentos descritos por Van Soest et al. (1991). As análises dos compostos nitrogênio não-protéico (NNP) foram realizadas segundo Licitra et al. (1996). Os carboidratos totais (CT) foram estimados por meio da equação descrita por Sniffen et al. (1992): $\mathrm{CT}=100-(\% \mathrm{~PB}+\% \mathrm{EE}+\%$ Cinzas $)$ e os CNF, pela diferença entre CT e FDN. A composição químicobromatológica do feno, dos concentrados e das dietas encontra-se na Tabela 3 .

O comportamento ingestivo das novilhas foi avaliado a cada período experimental, durante dois dias consecuti$\operatorname{vos}$ (24ํㅡ e 25으 dias de cada período experimental). No primeiro dia de observação, 28 novilhas foram submetidas à avaliação visual, em intervalos de dez minutos, registran- do-se a freqüência de alimentação, ruminação e ócio, perfazendo um total de 144 observações por animal em 24 horas. Para obtenção do tempo (em minutos) despendido em alimentação, ruminação e mastigação, multiplicou-se a freqüência de cada atividade pelo tempo diário de observação, expresso em minutos. O monitoramento dos animais durante os dois dias foi feito por três duplas de observadores devidamente treinados para manter a padronização nas observações.

No segundo dia, foram avaliados cinco animais por tratamento ( 20 novilhas no total) durantes três períodos de 2 horas (de 10 às 12h; de 14 às 16h; e de 19 às 21h), medindo-se, com o auxílio de cronômetro digital, o tempo de mastigação merícica por bolo ruminal e o número de mastigações merícicas por bolo ruminal.

Em cada período de 2 horas, foi realizada a observação de três bolos ruminais por animal para obtenção do tempo médio despendido na mastigação de um bolo ruminal e do número médio de mastigações merícicas por bolo ruminal. $\mathrm{O}$ número de mastigações merícicas em 24 horas foi obtido pela multiplicação do tempo médio de ruminação (durante um dia de observação) pelo número de mastigações merícicas por minuto, enquanto o número médio de bolos ruminais no período de 24 horas correspondeu ao quociente do tempo médio de ruminação (24 horas) pelo tempo médio de mastigação por bolo durante o segundo dia de observação.

A eficiência de alimentação (g MS/h e g FDN/h) foi obtida mediante o quociente da quantidade de MS ou FDN 
consumida pelo animal no período de 24 horas pelo tempo total de alimentação. Do mesmo modo, a eficiência de ruminação (g MS/h e g FDN/h) equivaleu à divisão da quantidade de MS ou FDN consumida pelo animal no período de 24 horas pelo tempo total de alimentação.

Os dados foram analisados em delineamento de blocos casualizados, com quatro tratamentos (níveis de substituição do feno pela polpa cítrica), em que os animais foram distribuídos em sete blocos, de acordo com seu peso inicial. As análises estatísticas foram realizadas utilizando-se o SAEG (Sistema de Análise Estatística e Genética) (UFV, 1995), segundo o modelo teórico:

$$
\mathrm{Yij}=\mu+\mathrm{ti}+\mathrm{bj}+\mathrm{eij}
$$

em que: $\mathrm{Yij}=$ valor observado na parcela que recebeu a dieta $\mathrm{i}$ e se encontra no bloco $\mathrm{j} ; \mu=$ média geral; $\mathrm{ti}=$ efeito do nível de substituição $i$, sendo $i=0,16,6,33,3$ e 50\%; $\mathrm{bj}=$ efeito do bloco $\mathrm{j}$; e eij = efeito dos fatores não controlados dentro da parcela.

\section{Resultados e Discussão}

A distribuição das atividades de alimentação e ruminação ao longo do dia pode ser observada na Figura 1. A ingestão dos alimentos foi maior durante o dia $(75,68 \%$ da atividade de alimentação ocorreu no período de 6 às $18 \mathrm{~h}$ ). Segundo Dado \& Allen (1995), o consumo de MS é maior após o fornecimento da dieta. Miranda et al. (1999) forneceram uma única refeição às 8 h e observaram que $84,96 \%$ do tempo despendido em alimentação ocorreu durante o dia.

Neste experimento, a dieta foi fornecida duas vezes ao dia (às 7 e 18h) e o tempo despendido nas atividades de alimentação no período das 18 às 24 horas foi maior que no experimento de Miranda et al. (1999). A distribuição mais uniforme das atividades de alimentação durante as 24 horas do dia provavelmente também foi influenciada pela temperatura durante o período experimental (Tabela 1). Assim, a modificação no horário ou na freqüência de fornecimento da dieta ao animal ou qualquer outro fator que influencie o conforto térmico do animal pode modificar a distribuição percentual dos horários de alimentação em animais em confinamento.

Em comparação às observações de Miranda et al. (1999), a atividade de ruminação neste estudo foi influenciada pela freqüência e pelo horário de alimentação e distribuiu-se de forma mais eqüitativa durante o dia e a noite. Segundo Polli et al. (1996), a atividade de ruminação é influenciada pela atividade de alimentação e ocorre após o consumo do alimento, com o animal em estado de repouso. Nesta pesquisa, 58,5\% da atividade de ruminação ocorreu durante
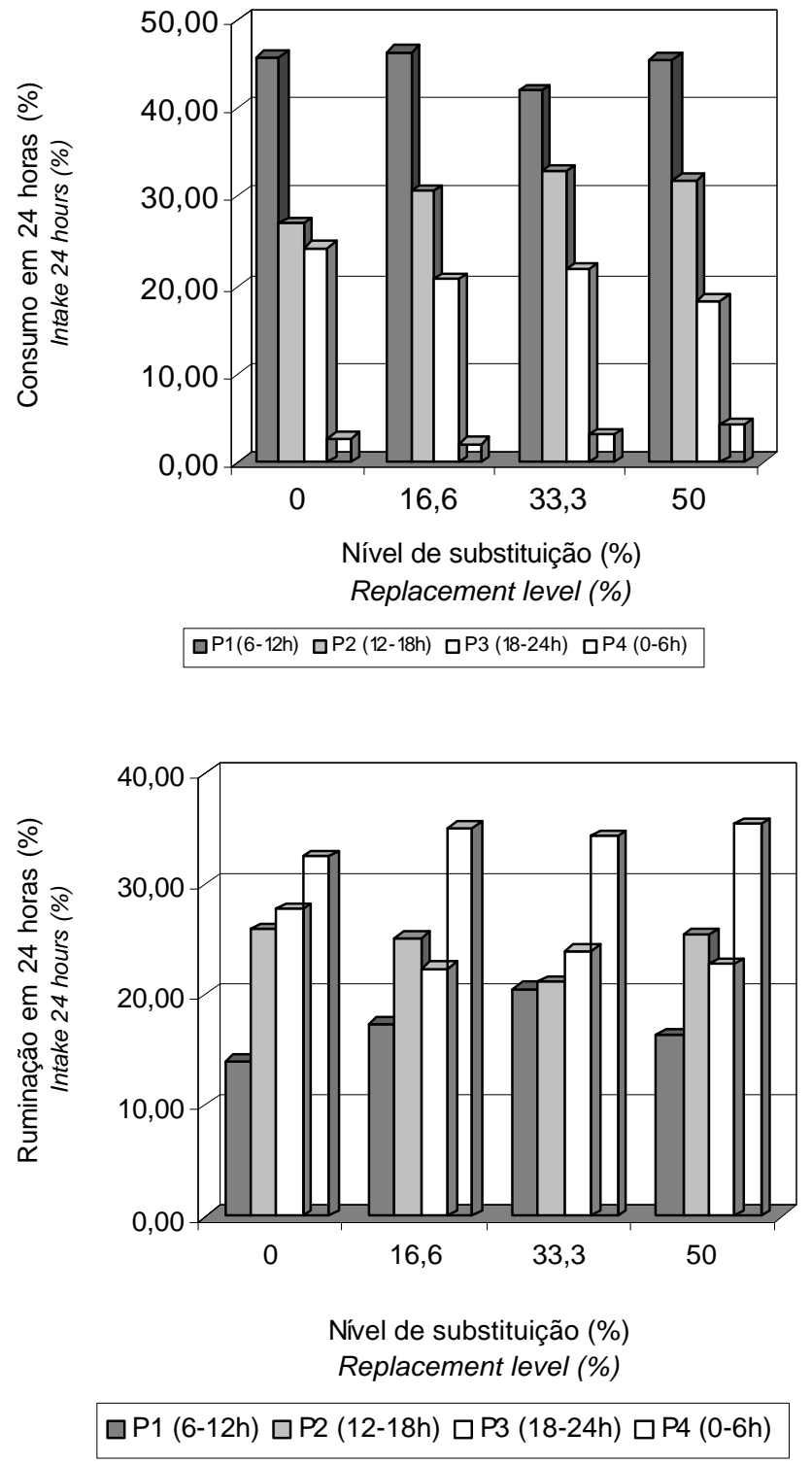

Figura 1 - Distribuição percentual das atividades de consumo e ruminação em quatro períodos $(1,2,3$ e 4$)$ do dia.

Figure 1- Eating and ruminating activities distributed in four periods (1, 2, 3, and 4) during the day.

a noite (18 às 6 h) e 41,5\% durante o dia (6 às $18 \mathrm{~h})$. No entanto, a atividade de ruminação ocorreu em maior intensidade durante a noite ( 0 às $6 \mathrm{~h}$ ), perfazendo, em média, $34,32 \%$ do tempo despendido nesta atividade.

Apesar do aumento no consumo de MS, os tempos gastos em alimentação, ruminação e mastigação total (Tabela 4), expressos em min/dia, diminuíram linearmente $(\mathrm{P}<0,10)$ com o aumento da substituição do feno pela polpa cítrica, o que, provavelmente, foi ocasionado pelo menor teor de FDN neste subproduto, resultando em menor consumo deste nutriente nos maiores níveis de substituição, e pela redução do tamanho das partículas (partículas longas 
Tabela 4 - Consumos médios diários de MS e FDN e comportamento ingestivo de novilhas alimentadas com dietas contendo diferentes níveis de polpa cítrica em substituição ao feno de tifton 85

Table 4 - $\quad$ Average daily intake of DM and NDF and chewing activity in heifers fed diets containing increasing levels of citrus pulp in replacement of Tifton 85 hay

\begin{tabular}{|c|c|c|c|c|c|c|c|}
\hline & \multicolumn{4}{|c|}{$\begin{array}{c}\text { Nível de substituição (\%) } \\
\text { Replacement level }\end{array}$} & \multirow[t]{2}{*}{$\mathrm{CV}$} & \multicolumn{2}{|l|}{$\mathrm{P}$} \\
\hline & 0 & 16,6 & 33,3 & 50 & & $\mathrm{~L}$ & Q \\
\hline \multicolumn{8}{|l|}{ Consumo (Intake) } \\
\hline $\mathrm{kg}$ MS/dia $(k g D M / d a y)^{1}$ & 6,97 & 7,31 & 7,75 & 8,35 & 8,64 & 0,0012 & $\mathrm{~ns}$ \\
\hline $\mathrm{kg}$ FDN/dia $(k g N D F / \text { day })^{2}$ & 3,58 & 3,37 & 3,19 & 3,00 & 9,97 & 0,0024 & $\mathrm{~ns}$ \\
\hline № médio de refeições/dia ${ }^{3}$ ( $N$. of meals/day) & 10,14 & 11,33 & 10,81 & 10,00 & 19,03 & $\mathrm{~ns}$ & $\mathrm{~ns}$ \\
\hline Tempo de consumo $(\mathrm{min} / \mathrm{dia})^{4}$ (Eating time, min/day) & 285,24 & 276,67 & 261,90 & 237,14 & 10,89 & 0,0032 & $\mathrm{~ns}$ \\
\hline \multicolumn{8}{|l|}{ Taxa de consumo (Eating rate) } \\
\hline $\min / \mathrm{kg}$ MS $(\min / \mathrm{kg} D M)^{5}$ & 44,76 & 42,77 & 35,48 & 29,85 & 15,25 & 0,0000 & $\mathrm{~ns}$ \\
\hline $\mathrm{min} / \mathrm{kg}$ FDN $(\min / \mathrm{kg} \mathrm{NDF})^{6}$ & 88,25 & 93,31 & 87,47 & 84,61 & 11,81 & $\mathrm{~ns}$ & $\mathrm{~ns}$ \\
\hline $\mathrm{kg}$ MS/refeição $(\mathrm{kg} \text { DM/meal })^{7}$ & 0,99 & 0,89 & 0,77 & 0,96 & 40,59 & ns & $\mathrm{ns}$ \\
\hline Duração das refeições $(\min )^{8}$ (Duration of meals) & 34,09 & 29,72 & 25,33 & 25,66 & 31,88 & 0,0735 & $\mathrm{~ns}$ \\
\hline № de períodos de ruminação/dia ${ }^{9}(N$. ruminating chews/day) & 16,33 & 16,44 & 17,57 & 16,57 & 11,25 & $\mathrm{~ns}$ & $\mathrm{~ns}$ \\
\hline Duração do período de ruminação (min) ${ }^{10}$ (Duration of ruminating chews) & ) 31,97 & 30,12 & 28,04 & 27,61 & 15,13 & 0,0563 & $\mathrm{~ns}$ \\
\hline Tempo de ruminação $(\mathrm{min} / \mathrm{dia})^{11}$ (Ruminating time, $\mathrm{min} /$ day $)$ & 512,38 & 487,78 & 480,95 & 454,29 & 7,59 & 0,0085 & $\mathrm{~ns}$ \\
\hline \multicolumn{8}{|l|}{ Taxa de ruminação (Ruminating rate) } \\
\hline $\mathrm{min} / \mathrm{kg} \mathrm{MS}(\min / \mathrm{kg} D M)^{12}$ & 108,13 & 105,21 & 99,31 & 91,48 & 13,13 & 0,0332 & $\mathrm{~ns}$ \\
\hline $\mathrm{min} / \mathrm{kg}$ FDN $(\mathrm{min} / \mathrm{kg} N D F)^{13}$ & 156,90 & 161,87 & 160,20 & 159,50 & 9,31 & $\mathrm{~ns}$ & $\mathrm{~ns}$ \\
\hline Tempo total de mastigação $(\mathrm{min} / \mathrm{dia})^{14}$ (Total chewing time, min/day) & 797,62 & 764,44 & 742,86 & 691,43 & 6,11 & 0,0003 & $\mathrm{~ns}$ \\
\hline \multicolumn{8}{|l|}{ Taxa de mastigação (Chewing rate) } \\
\hline $\mathrm{min} / \mathrm{kg}$ MS $(\min / \mathrm{kg} D M)^{15}$ & 124,58 & 117,03 & 100,61 & 86,20 & 12,61 & 0,0002 & $\mathrm{~ns}$ \\
\hline $\mathrm{min} / \mathrm{kg}$ FDN $(\mathrm{min} / \mathrm{kg} \mathrm{NDF})^{16}$ & 245,16 & 255,19 & 247,65 & 244,11 & 8,20 & $\mathrm{~ns}$ & ns \\
\hline
\end{tabular}

$1 \hat{Y}=6,25835+0,0229832 X\left(r^{2}=0,98\right) ;{ }^{2} \hat{Y}=3,29774-0,01106 X\left(r^{2}=0,99\right) ;{ }^{3} \hat{Y}=10,57 ;{ }^{4} \hat{Y}=292,411-1,00460 X\left(r^{2}=0,89\right) ;{ }^{5} \hat{Y}=46,3215-0,316869 X$ $\left(r^{2}=0,94\right) ;{ }^{6} \hat{Y}=88,41 ;{ }^{7} \hat{Y}=0,90 ; 8 \hat{Y}=32,8422-0,174892 X\left(r^{2}=0,85\right) ;{ }^{9} \hat{Y}=16,73 ; 10 \hat{Y}=31,7911-0,0922831 X\left(r^{2}=0,95\right) ; 11 \hat{Y}=511,966-1,10118 X$ $\left(r^{2}=0,97\right) ;{ }^{12} \hat{Y}=107,510-0,306613 X\left(r^{2}=0,94\right) ;{ }^{13} \hat{Y}=159,62 ;{ }^{14} \hat{Y}=804,378-2,10578 X\left(r^{2}=0,97\right) ; 15 \hat{Y}=127,009-0,792223 X\left(r^{2}=0,98\right) ;{ }^{16} \hat{Y}=247,77$

do feno de tifton foram subtituídas por partículas pequenas da polpa cítrica moída). Estes resultados corroboram as observações de Van Soest (1994) de que o tempo despendido na alimentação é proporcional ao teor de FDN das dietas.

Observou-se redução linear $(\mathrm{P}<0,01)$ nas taxas de consumo, ruminação e mastigação total com o aumento dos níveis de substituição do feno pela polpa cítrica na dieta. Essa redução pode ser comprovada pelo tempo despendido nestas atividades por quilograma de MS ingerida e, provavelmente, foi ocasionada pelo menor teor de FDN e pela diminuição no tamanho de partículas da dieta à medida que o feno foi substituído pela polpa cítrica (Welch \& Hooper, 1988; Johnson \& Combs, 1992; Albright, 1993). Com a substituição do feno pela polpa cítrica o teor de carboidratos totais permaneceu praticamente constante (Tabela 3), no entanto, ocorreu substituição linear dos carboidratos fibrosos pelos não-fibrosos, contribuindo para a redução no tempo gasto em consumo, ruminação e mastigação total (min/dia). Portanto, a mudança na composição da dieta e a menor necessidade de trituração das partículas de polpa cítrica resultaram em menor tempo despendido (min/dia) nas atividades de consumo, ruminação e mastigação e, conseqüentemente, nas taxas de consumo, ruminação e mastigação total em $\mathrm{min} / \mathrm{kg}$ de MS.

Não houve efeito das dietas sobre as taxas de consumo, ruminação e mastigação total expressas em min/kg FDN. Portanto, a redução no tempo despendido nessas atividades em min/dia foi proporcional ao teor de FDN das dietas. Welch \& Smith (1971) estudaram o efeito do consumo de polpa de beterraba e polpa cítrica na atividade de ruminação de cordeiros e novilhas leiteiras. Esses autores observaram que o tempo de mastigação por unidade de MS consumida (min/kg MS) nos animais alimentados com as dietas contendo polpa cítrica foi menor que naqueles que receberam a dieta com feno. Esses autores não constataram, no entanto, efeito no tempo de ruminação por unidade de parede celular (min/kg FDN) nos animais alimentados com as dietas com feno e polpa cítrica, o que também foi verificado neste estudo.

Schaibly \& Wing (1974) substituíram 33, 67 e 100\% da silagem de milho pela polpa cítrica e observaram redução no pH ruminal com o aumento dos níveis de substituição. Essa redução, porém, foi menos acentuada que a esperada para outros concentrados. Neste experimento, não foi observada 
redução nas taxas de alimentação, ruminação e mastigação total expressas em min/kg FDN. Logo, não apenas o padrão de fermentação da polpa cítrica, em que o alto teor de pectina produz maior proporção de ácido acético em detrimento aos ácidos lático e propiônico (Van Soest, 1994), como também a capacidade da fração fibrosa da polpa em manter as taxas de alimentação, ruminação e mastigação total ( $\mathrm{min} / \mathrm{kg}$ FDN) pode ser responsável pelos resultados observados na literatura e a indicação de que a polpa cítrica pode ser utilizada em dietas para ruminantes, principalmente quando as dietas contêm elevada relação concentrado:volumoso, como forma de manter o ambiente ruminal mais estável.

A menor duração das refeições durante a alimentação e dos períodos ruminação $(\mathrm{P}<0,05)$ com o aumento da substituição do feno pela polpa cítrica provavelmente é decorrente do menor teor de FDN das dietas. O número de refeições, no entanto, e os períodos de ruminação não foram afetados pelas dietas experimentais.

A substituição do feno pela polpa cítrica não afetou o número de mastigações merícicas por dia, a taxa de mastigação, o número de mastigações merícicas por bolo, o tempo de mastigações merícicas por bolo e o número de bolos por dia (Tabela 5). Os resultados obtidos estão de acordo com os encontrados por Thiago et al. (1992), que relataram que a quantidade de alimento consumido por um ruminante em determinado período depende do número de refeições nesse período, da duração das refeições e da taxa de alimentação, ou seja, do tempo gasto por quilograma de MS consumida. Neste experimento, o consumo de MS em kg de MS/dia aumentou ( $\mathrm{P}<0,10)$ com o aumento da substituição do feno pela polpa. Desse modo, o número de períodos de alimentação não foi alterado, mas houve compensação comprovada pela diminuição $(\mathrm{P}<0,01)$ no tempo por refeição e pelo aumento $(\mathrm{P}<0,10)$ na taxa de alimentação, expressos em min/kg de MS, não influenciando, no entanto, as características de mastigação (Tabela 5).

As médias de eficiência de alimentação e ruminação são apresentadas na Tabela 6 . Foi observada maior $(\mathrm{P}<0,10)$ eficiência de alimentação e ruminação em $\mathrm{g} \mathrm{MS} / \mathrm{h}$ com a substituição do feno pela polpa cítrica, o que pode ser explicado pela redução no teor de FDN das dietas. No entanto, as eficiências de alimentação e ruminação em $g$ FDN/h não foram afetadas pelos níveis de substituição do feno pela polpa. Os resultados observados corroboram as observações de Welch \& Smith (1971) de que a fração fibrosa da polpa cítrica é efetiva na manutenção das atividades de alimentação, ruminação e mastigação, sendo importante para redução nas variações no ambiente ruminal, principalmente em animais de elevada produção, nos quais

Tabela 5 - Mastigações merícicas em novilhas alimentadas com dietas contendo polpa cítrica em substituição ao feno de tifton 85 Table 5 - Rumination chews in heifers fed diets containing increasing levels of citrus pulp in replacement of Tifton 85 hay

\begin{tabular}{|c|c|c|c|c|c|c|c|}
\hline & \multicolumn{4}{|c|}{$\begin{array}{c}\text { Nível de substituição (\%) } \\
\text { Replacement level }\end{array}$} & \multirow[t]{2}{*}{$\mathrm{CV}$} & \multicolumn{2}{|c|}{$\mathrm{P}$} \\
\hline & 0 & 16,6 & 33,3 & 50 & & $\mathrm{~L}$ & Q \\
\hline № de mastigações merícicas/dia (Rumination chews per day) & 35.253 & 33.926 & 33.486 & 32.011 & 14,51 & ns & $\mathrm{ns}$ \\
\hline № de mastigações merícicas/min (Rumination chews per minute) & 67,94 & 68,42 & 69,44 & 67,63 & 6,86 & $\mathrm{~ns}$ & $\mathrm{~ns}$ \\
\hline № de mastigações merícicas/bolo (Rumination chews per bolus) & 65,15 & 62,56 & 57,82 & 66,34 & 14,51 & ns & $\mathrm{ns}$ \\
\hline Tempo de mastigações merícicas/bolo (s) (Rumination chews per bolus) & 57,82 & 54,73 & 49,06 & 59,16 & 9,89 & $\mathrm{~ns}$ & $\mathrm{~ns}$ \\
\hline № de bolos/dia (Number of ruminal bolus per day) & 554 & 569 & 611 & 495 & 11,62 & $\mathrm{~ns}$ & $\mathrm{~ns}$ \\
\hline
\end{tabular}

$1 \hat{\mathrm{Y}}=33669,40 ;{ }^{2} \hat{\mathrm{Y}}=68,36 ;{ }^{3} \hat{\mathrm{Y}}=62,97 ;{ }^{4} \hat{\mathrm{Y}}=55,42 ;{ }^{5} \hat{\mathrm{Y}}=557,56$

Tabela 6 - Eficiências de alimentação e ruminação da MS e FDN em novilhas alimentadas com dietas contendo polpa cítrica em substituição ao feno de tifton

Table 6 - Eating and ruminating efficiencies of DM and NDF in heifers fed diets containing increasing levels of citrus pulp in replacement of Tifton 85 hay

\begin{tabular}{|c|c|c|c|c|c|c|c|}
\hline & \multicolumn{4}{|c|}{$\begin{array}{c}\text { Nível de substituição (\%) } \\
\text { Replacement level }\end{array}$} & \multirow[t]{2}{*}{$\mathrm{CV}$} & \multicolumn{2}{|c|}{$\mathrm{P}$} \\
\hline & 0 & 16,6 & 33,3 & 50 & & $\mathrm{~L}$ & Q \\
\hline Eficiência de alimentação $(\mathrm{g} \text { MS/h})^{1}$ (Eating efficiency, g $D M / h$ ) & $1.535,80$ & $1.655,20$ & $1.801,12$ & $2.229,46$ & 15,52 & 0,0001 & $\mathrm{~ns}$ \\
\hline Eficiência de alimentação (g FDN/h $)^{2}$ (Eating efficiency, g NDF/h) & 792,67 & 764,58 & 742,91 & 801,91 & 14,90 & $\mathrm{~ns}$ & $\mathrm{~ns}$ \\
\hline Eficiência de ruminação $(\mathrm{g} \mathrm{MS} / \mathrm{h})^{3}$ (Ruminating efficiency, $g$ DM/h) & 823,49 & 913,40 & 986,01 & $1.121,15$ & 9,66 & 0,0000 & $\mathrm{~ns}$ \\
\hline Eficiência de ruminação $\left(\mathrm{g}\right.$ FDN/h) ${ }^{4}$ (Ruminating efficiency, g NDF/h) & 423,41 & 420,75 & 405,94 & 402,58 & 9,85 & $\mathrm{~ns}$ & $\mathrm{~ns}$ \\
\hline
\end{tabular}

${ }^{1} \hat{Y}=1448,91+13,7055 X\left(r^{2}=0,89\right) ;{ }^{2} \hat{Y}=775,52 ;{ }^{3} \hat{Y}=811,726+5,86224 X\left(r^{2}=0,98\right) ;{ }^{4} \hat{Y}=413,17$ 
geralmente se recorre a dietas com grande quantidade de concentrado. Segundo esses autores, em situações práticas, no caso de dietas formuladas com elevada proporção de concentrado, a utilização de polpa cítrica deve ser limitada, em virtude de seu baixo teor de FDN. No entanto, como neste estudo as eficiências de alimentação e ruminação em g FDN/h não foram influenciadas pela substituição do feno de tifton pela polpa cítrica, a polpa pode ser utilizada em larga escala (35\% da dieta total) desde que atendido o requerimento mínimo de fibra recomendado pelo NRC $(1989,2001)$.

\section{Conclusões}

O baixo teor de FDN da polpa cítrica promove modificações no comportamento ingestivo dos animais. A polpa cítrica pode ser utilizada em até $35 \%$ da dieta total de novilhas leiteiras desde que associada a outros ingredientes de forma a atender às exigências mínimas de FDN e evitar distúrbios metabólicos.

\section{Literatura Citada}

ALBRIGHT, J.L. Feeding behavior of dairy cattle. Journal of Dairy Science, v.76, n.2, p.478-498, 1993.

BEAUCHEMIN, K.A.; McALLISTER, T.A.; DONG, Y. et al. Effects of mastication on digestion of whole cereal grains by cattle. Journal of Animal Science, v.72, n.1, p.236-246, 1994.

DESWYSEN, A.G.; ELLIS, W.C.; POND, K.R. Interrelationships among voluntary intake, eating and ruminating behavior and ruminal motility of heifers fed corn silage. Journal of Animal Science, v.64, n.3, p.835-841, 1987.

DADO, R.G.; ALLEN, M.S. Intake limitations, feeding behavior, and rumen function of cows challenged with rumen fill from dietary fiber or inert bulk. Journal of Dairy Science, v.78, n.1, p.118-133, 1995.

JOHNSON, T.R.; COMBS, D.K. Effects of inert rumen bulk on dairy matter intake in early and midlactacion cows fed diets differing in forage content. Journal of Dairy Science, v.75, n.2, p.508-519, 1992 .

LICITRA, G.; HERNANDEZ, T.M.; Van SOEST, P.J. Standardization of procedures for nitrogen fractionation of ruminant feeds. Animal Feed Science and Technology, v.57, p.347-358, 1996 .

MIRANDA, L.F.; QUEIROZ, A.C.; VALADARES FILHO, S.C. et al. Comportamento ingestivo de novilhas leiteiras alimentadas com dietas à base de cana-de-açúcar. Revista Brasileira de Zootecnia, v.28, n.3, p.614-620, 1999.
NATIONAL RESEARCH COUNCIL - NRC. Nutrient requirements of dairy cattle. 6.ed. Washington, D.C.: Academic Press, 1989. 158p.

NATIONAL RESEARCH COUNCIL - NRC. Nutrient requirements of dairy cattle. 7.ed. Washington, D.C.: Academic Press, 2001. 381p.

POLLI, V.A.; RESTLE, J.; SENNA, D.B. Aspectos relativos à ruminação de bovinos e bubalinos em regime de confinamento. Revista Brasileira de Zootecnia, v.25, n.5, p.987-993, 1996.

POPPI, D.P.; HUGHES, T.P.; L'HUILLIER, P.J. Intake of pasture by grazing ruminants. In: NICOL, A.M. (Ed.). Livestock feeding on pasture. Ruakura: New Zealand Society of Animal Production, 1987. p.55-64

SCHAIBLY, G.E.; WING, J.M. Effects of roughage concentrate ratio on digestibility and rumen fermentation of corn silagecitrus pulp rations. Journal of Animal Science, v.38, n.3, p.697-701, 1974.

SILVA, P.R.C. Análise de alimentos (métodos químicos e biológicos). Viçosa, MG: Universidade Federal de Viçosa, 1990. $165 \mathrm{p}$.

SNIFFEN, C.J.; O'CONNOR, J.D.; Van SOEST, P.J. et al. A net carbohydrate and protein system for evaluating cattle diets: II - Carbohydrate and protein availability. Journal of Animal Science, v.70, p.3562-3577, 1992.

THIAGO, L.R.L.; GILL, M.; SISSONS, J.W. Studies of conserving grass herbage and frequency of feeding in cattle. British Journal of Nutrition, v.67, n.3, p.339-346, 1992

UNIVERSIDADE FEDERAL DE VIÇOSA - UFV. S.A.E.G. (Sistema de Análises Estatísticas e Genéticas). Viçosa, MG: Fundação Arthur Bernanrdes, 1995. (Versão 5.0). CD-ROM

ULYATT, M.J.; FOX, D.G.; PERRY, T.C. et al. Influence of roughage and grain processing in high-concentrate diets on the performance of long-fed steers. Journal of Animal Science, v.73, n.7, p.1888-1900, 1995 .

Van SOEST, P.J. Nutritional ecology of the ruminant. 2.ed. Ithaca: Cornell, 1994. 476p.

Van SOEST, P.J.; ROBERTSON, J.B.; LEWIS, B.A. Methods for dietary fiber, and nonstarch polysaccharides in relation to animal nutrition. Journal of Dairy Science, v.74, n.10, p.35833597,1991

WELCH, J.G.; HOOPER, A.P. Ingestion of feed and water. In CHURCH, D.C. (Ed.). The ruminant animal: digestive physiology and nutrition. Englewood Cliffs: Reston, 1988. p. 108-116.

WELCH, J.G. Rumination, particle size and passage from the rumen. Journal of Animal Science, v.54, n.4, p.885-894, 1982

WELCH, J.G.; SMITH, A.M. Effects of beet pulp and citrus pulp on rumination activity. Journal of Animal Science, v.33, n.2, p.472-475, 1971 . 